\title{
Contribuições do Satepsi para Avaliações Psicológicas Compulsórias (Trânsito, Porte de Arma e Concursos Públicos)
}

\author{
Cristiane Faiad ${ }^{1}$ \\ ${ }^{1}$ Universidade de Brasília, DF, Brasil.
}

\author{
Irai Cristina Boccato Alves ${ }^{2}$ \\ ${ }^{2}$ Universidade de São Paulo, SP, Brasil.
}

Resumo: Por avaliação psicológica compulsória, entende-se uma avaliação de caráter obrigatório, quando o indivíduo deve realizá-la por alguma exigência legal, em cumprimento a alguma exigência normativa. Dentre os exemplos mais comuns existentes no Brasil e que se aplicam a esta avaliação estão a realizada para obtenção ou renovação da Carteira Nacional de Habilitação para motoristas do Detran, a avaliação psicológica no contexto de concursos públicos, a avaliação para manuseio de arma de fogo, dentre outras. O objetivo do presente artigo é apresentar um panorama geral dessas avaliações e discutir, acima de tudo, as contribuições que o Satepsi realizou para a melhoria dessas práticas. Apresentou-se inicialmente um histórico das normativas construídas pelo Conselho Federal (CFP), nos últimos 15 anos e para cada uma dessas práticas, algumas das normas e ações realizadas pelo CFP para seu aprimoramento. Apesar de claras contribuições, entende-se que muitos investimentos no campo da pesquisa ainda precisam ser realizados para melhor subsidiar a atuação dos psicólogos e psicólogas de cada uma das áreas.

Palavras-chave: Avaliação Compulsória, Concurso Público, Detran, Porte de Arma.

\section{Satepsi's Contributions to Compulsory Psychological Assessments (Traffic, Weapons Carry and Public Contexts)}

\begin{abstract}
By compulsory psychological assessment it is understood an evaluation of a mandatory nature, when a person must perform it for some legal requirement, in compliance with some normative requirement. Among the most common examples that exist in Brazil and that apply to this evaluation are those performed to obtain or renew the National Drivers License for Detran, psychological assessment in the public context, evaluation to carry weapons, among others. The purpose of this article is to present an overview of these evaluations and to discuss, above all, the contributions that Satepsi has made to improve these practices. Initially, we present a history of the regulations built by the Federal Council in the last 15 years and for each of these practices, and some of the standards and actions carried out by the CFP for its improvement. Despite clear contributions, it is understood that many investments in the field of research still need to be performed to better subsidize the performance of psychologists in each of these fields.
\end{abstract}

Keywords: Compulsory, Public Context, Traffic, Weapons Carry. 


\title{
Contribuciones del Satepsi para Evaluaciones Psicológicas Compulsivas (Tránsito, Porte de Arma y Concursos Públicos)
}

\begin{abstract}
Resumen: Por evaluación psicológica obligatoria, se entiende una evaluación de carácter obligatorio, cuando el individuo debe realizarla por alguna exigencia legal, en cumplimiento a alguna exigencia normativa. Entre los ejemplos más comunes en Brasil y que se aplican a esta evaluación, se destacan, la realizada para la obtención o renovación de la Carnet Nacional de Habilitación para conductores del Detran, la evaluación psicológica en el contexto de concursos públicos, la evaluación para manejo de arma de fuego, entre otras. El objetivo del presente artículo es presentar un panorama general de esas evaluaciones y discutir, sobre todo, las contribuciones que el Satepsi realizó para la mejora de esas prácticas. Se presentó inicialmente un histórico de las normativas construidas por el Consejo Federal (CFP), en los últimos 15 años y para cada una de esas prácticas, algunas de las normas y acciones realizadas por el CFP para su perfeccionamiento. A pesar de claras contribuciones, se entiende que muchas inversiones en el campo de la investigación todavía necesitan ser realizadas para mejor subsidiar la actuación de los psicólogos y psicólogas de cada una de las áreas.
\end{abstract}

Palabras clave: Evaluación Obligatoria, Concurso Público, Detran, Porte de Arma.

O Satepsi é o Sistema de Avaliação de Testes Psicológicos, que foi criado pelo Conselho Federal de Psicologia (CFP), com o objetivo de divulgar informações sobre os testes psicológicos para os psicólogos. A criação do Satepsi ocorreu dentro de um contexto em que uma gama de testes psicológicos era utilizada, mas muitos deles não apresentavam manual de aplicação e de avaliação. Os testes eram aplicados com instruções improvisadas e variadas, não apresentando nenhuma padronização, o que comprometia os resultados obtidos nas avaliações. O material dos testes também não era padronizado. Os manuais, quando existentes, não apresentavam fundamentação teórica, instruções de aplicação detalhadas, instruções para avaliação, tabelas normativas e informações sobre a validade e precisão do teste. E, quando incluíam alguns dados estatísticos, estes eram incompletos e sem descrição de como ou quando foram obtidos.

Mansur-Alves, Silva e Fernandes (2016) destacam a posição apresentada por por Anache e Corrêa (2010) e de Primi e Nunes (2010),de que o Satepsi pode ser considerado como um sistema de certificação nacional da qualidade técnica e científica dos testes psicológicos comercializados em nosso país. Essa certificação seria atribuída com base nos requisitos técnicos mínimos, ou seja, na apresentação da fundamentação teórica do teste, e de estudos de validade, precisão e padronização, baseadas em regras internacionais.
A avaliação psicológica (AP) constitui um processo técnico científico que permite acessar, partindo de uma demanda inicial, aspectos psicológicos, cognitivos e conativos de um indivíduo ou de um grupo (Primi, 2014). A partir de seu resultado, espera-se que minimamente esta consiga trazer subsídios para tomada de uma decisão ou fazer uso desses dados para um devido acompanhamento do ou dos avaliados. Tal definição traz um grande desafio, quando se começa a pensar nos diferentes contextos em que a avaliação pode ser aplicada e nas especificidades que cada tipo resguarda. Destes, possivelmente as avaliações compulsórias contabilizam o maior número de avaliações realizadas no Brasil.

Por avaliação psicológica compulsória, entende-se uma avaliação que tem um caráter de obrigatoriedade. Neste sentido, o indivíduo deve realizá-la por alguma exigência legal, em cumprimento a alguma exigência normativa. Dentre os exemplos mais comuns existentes no Brasil e que se aplicam na avaliação compulsória, estão a avaliação relativa à obtenção ou renovação da Carteira Nacional de Habilitação (CNH) para motoristas do Detran (Silva, Alves, \& Rosa, 2015), a avaliação psicológica no contexto de concursos públicos (Thadeu, Ferreira, \& Faiad, 2012), a avaliação para manuseio de arma de fogo (Caneda, \& Teodoro, 2012).que serão foco de análise deste artigo - bem como as avaliações baseadas em Normas Regulamentadoras NR33 (espaço confinado) e NR35 (altura), (Guimarães, 
Martins, \& Botelho, 2013), avaliação bariátrica (Justino, Barbosa, \& Pimentel, 2017), dentre outras. Assim, serão apresentadas algumas particularidades de cada uma dessas avaliações e discutidas as contribuições realizadas pelo Satepsi para essas situações.

Em relação à avaliação psicológica, em 2001 o CFP estabeleceu a Resolução $n^{\circ}$ 025/2001, cujo objetivo era definir e regulamentar o uso, a elaboração e a comercialização dos testes psicológicos. No Art. $1^{\circ}$, definiu os testes psicológicos "como instrumentos de avaliação ou mensuração de características psicológicas, constituindo-se um método ou uma técnica de uso privativo do psicólogo, em decorrência do que dispõe o $\$ 1^{\circ}$ do Art. 13 da Lei no ${ }^{\circ} 4.119 / 62 "$.

Esse artigo possui um parágrafo único que define os testes psicológicos como "procedimentos sistemáticos de observação e registro de amostras de comportamentos e respostas de indivíduos com o objetivo de descrever e/ou mensurar características e processos psicológicos, compreendidos tradicionalmente nas áreas emoção/afeto, cognição/inteligência, motivação, personalidade, psicomotricidade, atenção, memória, percepção, dentre outras, nas suas mais diversas formas de expressão, segundo padrões definidos pela construção dos instrumentos" (Lei n ${ }^{\circ}$ 4.119/62).

Em 2003 o CFP estabeleceu a Resolução $n^{\circ}$ $002 / 2003$, que "define e regulamenta o uso, a elaboração e a comercialização de testes psicológicos e revoga a Resolução CFP n ${ }^{\circ}$ 025/2001". Nos artigos 3 e 4 estabelece que os testes psicológicos, "que utilizam questões de múltipla escolha e outros similares, tais como 'acerto e erro', 'inventários' e 'escalas', devem apresentar obrigatoriamente os requisitos mínimos previstos na Resolução para que possam ser empregados pelos psicólogos.

Os requisitos mínimos foram a apresentação da fundamentação teórica e de evidências empíricas de validade e precisão e das interpretações propostas para os escores do teste, bem como das propriedades psicométricas dos itens. Também deveria ser apresentado o sistema de correção e interpretação dos escores, indicando a lógica que fundamenta o procedimento, em função do sistema de interpretação adotado, que pode ser referenciada à norma ou diferente da interpretação referenciada à norma, justificando a lógica do procedimento de interpretação utilizado. Deveriam ser indicados também os procedimentos de aplicação e correção, de modo a obter uniformidade dos procedimentos envolvidos na sua aplicação. Essas informações deveriam estar presentes no manual do teste, e abranger os aspectos técnico-científicos, práticos e a literatura científica sobre o teste (Resolução ${ }^{\circ} 002 / 2003$ ).

A Resolução também instituiu em seu Art. 8, que:

o CFP manterá uma Comissão Consultiva em Avaliação Psicológica integrada por psicólogos convidados, de reconhecido saber em testes psicológicos, com o objetivo de analisar e emitir parecer sobre os testes psicológicos encaminhados ao CFP, com base nos parâmetros definidos nesta Resolução, bem como apresentar sugestões para o aprimoramento dos procedimentos e critérios envolvidos nessa tarefa, subsidiando as decisões do Plenário a respeito da matéria (Resolução nº 002/2003).

A partir dessa Resolução foi criado o Satepsi, inserindo-se como um dos maiores marcos na área de Avaliação Psicológica no Brasil, implantado em 2003 e proposto com o objetivo de qualificar os instrumentos usados pelos psicólogos. Dessa forma, uma comissão de especialistas passou a analisar sistematicamente, se os testes usados para fins diagnósticos permitiam que as interpretações dos resultados obtidos a partir do seu uso fossem respaldadas teórica e empiricamente.

O Satepsi teve um papel preponderante também nas avaliações compulsórias. Conforme apontado por Noronha et al. (2003) e Reppold, Serafini, Ramires e Gurgel (2017), até então o panorama brasileiro dos testes psicológicos passava por uma fase de descrédito, pela falta de qualidade técnico-científica das informações disponíveis sobre os testes utilizados na época (Nakano, 2013). Dentre os maiores problemas enfrentados naquela época estavam o uso de testes internacionais não adaptados de forma correta (Borsa, Damásio, \& Bandeira, 2012); o uso de medidas sem nenhuma validade (Noronha, 2002); a falta de qualidade nas práticas profissionais (Santos, 2016), dentre tantas outras limitações. Tais problemas afetaram, consequentemente, não apenas a qualidade das avaliações compulsórias, mas, também, levantaram vários questionamentos sobre sua validade e continuidade.

Consequentemente, ainda no início da década de 2000, houve um aumento considerável na produção nacional de testes psicológicos, alinhado a um aumento na sua qualidade (Reppold et al., 2017). Tais melhorias estavam também vinculadas à criação de uma Comissão Consultiva de Avaliação Psicológica (CCAP), composta por especialistas na área de construção de medidas e psicometria, responsável pela análise 
dos testes. Outro importante papel desta Comissão foi relativo à construção e publicação de Resoluções que passaram a orientar o processo de construção e medidas e, como grande destaque para área, documentos normativos para algumas das práticas psicológicas que vinham sendo realizadas no Brasil.

Mansur-Alves et al. (2016) destacaram a progressão do número de publicações sobre a avaliação psicológica entre os anos de 1994 e 2014, com um pico acentuado no ano de 2002. As autoras consideraram que a criação do Satepsi incentivou as investigações sobre a avaliação psicológica em diferentes contextos, em relação ao período anterior à Resolução $\mathrm{n}^{\circ}$ 02/2003. Foi a partir deste documento que a qualidade das avaliações psicológicas no Brasil ficou evidenciada, visto que os instrumentos ora utilizados no Brasil já detinham uma análise prévia da CCAP, divulgada por meio de uma lista pública de acesso aos psicólogos e também à sociedade e que permitiam uma escolha de medidas mais adequadas.

Embora tenha sido um avanço, houve também um forte impacto negativo causado nas avaliações psicológicas a partir da implantação do Satepsi. Isso ocorreu pela forma como lista dos testes aprovados pela Comissão foi divulgada pela imprensa à época, que trouxe sérios danos à imagem do psicólogo e dos testes psicológicos. A mensagem veiculada para o público foi de que os testes não valiam nada e que as avaliações não eram sérias. Entretanto, não foi apresentada a informação sobre o real significado dessa lista, porque muitas vezes um teste não foi aprovado, simplesmente porque o seu manual não estava atualizado, ainda que o teste fosse bom. Esta imagem foi significativamente melhorada à medida que os manuais dos testes publicados foram atualizados, atendendo às exigências da Resolução n ${ }^{\circ} 02 / 2003$. Afinal, os testes aprovados que apresentavam as normas e estudos sobre a precisão e validade para a nossa população tornaram as avaliações psicológicas mais confiáveis e podendo cumprir a sua função de avaliação, com base em dados relativos à população brasileira. Além disso, os testes podiam realmente avaliar a característica investigada com dados apropriados para a nossa população.

No ano de 2018, houve mais uma importante contribuição aos processos de avaliação psicológica no Brasil. Foi publicada a Resolução ${ }^{\circ}$ 09/2018 (que revogou as Resoluções $n^{\circ} 002 / 2003, n^{\circ} 006 / 2004, n^{\circ}$ 005/2012 e as Notas Técnicas no 01/2017 e n ${ }^{\circ} 02 / 2017$ ). Para além da definição do processo de regulamenta- ção do uso, da construção de medidas e da definição de requisitos mínimos para avaliação e comercialização dos instrumentos, o documento acrescentou a possibilidade de que psicólogas e psicólogos se resguardassem de uma maior segurança na tomada de decisão, por meio da escolha de métodos, técnicas e/ ou instrumentos na tomada de decisão.

No Art. 2, a Resolução n ${ }^{0}$ 09/2018 reforça a necessidade de que as decisões sobre os processos de avaliação sejam tomadas com base em caráter científico, centradas no uso de "métodos e/ou técnicas e/ou instrumentos psicológicos" identificados como fontes fundamentais de informação (testes aprovados, entrevistas e protocolos de observação). Acrescentam, ainda, a possibilidade de que fontes complementares de informações também possam ser aplicadas, a depender do contexto, referindo-se a técnicas e instrumentos não psicológicos e relatórios multiprofissionais. Contudo, uma importante colocação é referenciada ao estabelecer que apenas as fontes fundamentais podem ser utilizadas para tomada de decisão sobre o resultado da pessoa avaliada.

A partir desse panorama histórico das contribuições do Satepsi, observa-se que o psicólogo e psicóloga que trabalham na ponta, que trabalham em diferentes contextos de avaliação psicológica, passaram a ter mais embasamento científico para sua prática. E ao discutir outros avanços que ocorreram nas avaliações compulsórias, o presente manuscrito discute a seguir três dessas avaliações, sendo elas o trânsito, o concurso público e o porte de arma de fogo.

\section{Avaliação Psicológica no trânsito}

Na história da Psicologia, a primeira experiência de avaliação psicológica de motoristas foi feita em 1912 pelo alemão Hugo Münsterberg, radicado nos Estados Unidos. No Brasil as primeiras avaliações de condutores de que se tem conhecimento ocorreram por volta de 1928, durante a criação do Laboratório de Psicotécnica da Estrada de Ferro Sorocabana (SP), em função da instalação das vias férreas e a consequente urgência na seleção de maquinistas (Hoffman, 1996, apud Alchieri \& Stroher, 2002). Contudo, as primeiras avaliações psicológicas de motoristas foram realizadas em 1951, pelo ISOP (Instituto de Seleção e Orientação Profissional) da Fundação Getúlio Vargas.

Segundo Rueda e Monteiro (2012), em 1953 o Conselho Nacional de Trânsito (Contran) tornou obrigatório o exame psicológico para os candidatos à profissão de motoristas, que foi chamado de "exame psicotécnico" e, 
em 1962, ele abrangeu todos os candidatos a motoristas. Desde então, o exame psicotécnico passou por várias modificações, sendo quase excluído do processo de obtenção da CNH em 1997, em função da sanção do presidente da República ao Novo Código de Trânsito Brasileiro, cujo item referente à obrigatoriedade da avaliação psicológica do candidato havia sido vetado. No entanto, graças à mobilização dos psicólogos e das orientações do Departamento Nacional de Trânsito (Denatran) foi formulada a Resolução ${ }^{\circ}$ 80/1998, que regulamentou a avaliação psicológica de candidatos à CNH (Alves, 1999).

A Resolução no 80/1998 determinava que as características psicológicas que deveriam ser avaliadas fossem as áreas percepto-reacional, motora e nível mental, o equilíbrio psíquico e habilidades específicas, entre as quais se encontra a atenção. Segundo esta resolução, o psicólogo para atuar nesta área deveria:

ter, no mínimo, um ano de formado; estar com o registro de psicólogo atualizado no respectivo Conselho Regional de Psicologia; ter experiência de um ano na área de avaliação psicológica; e ter concluído o Curso de Capacitação para psicólogo responsável pela avaliação psicológica e como Psicólogo Perito Examinador do Trânsito.

Assim, para realizar o "psicotécnico" o psicólogo tem o dever de conhecer e seguir rigorosamente as especificações contidas nos manuais dos testes utilizados, para que os resultados sejam considerados válidos.

Em 2008, foram apresentadas novas especificações sobre as áreas a serem avaliadas e a qualificação profissional do psicólogo na Resolução 267 do Contran e, em 2009, o CFP publicou a Resolução ${ }^{\circ}$ 007/2009, estabelecendo normas e procedimentos para a avaliação psicológica no contexto do trânsito, descrevendo quais características deveriam ser avaliadas. Entre essas características a Resolução indicou que os candidatos deveriam ser avaliados nos diferentes tipos de atenção, ou seja, atenção difusa, vigilância, atenção sustentada, atenção concentrada, distribuída, atenção dividida e atenção alternada.

Um exemplo da importância da avaliação psicológica no contexto do trânsito é apresentado no artigo de Fontana e Fegadolli (2016), em que as autoras apresentaram o caso de um motorista avaliado para a renovação da $\mathrm{CNH}$, que dirigia, na época, um caminhão, do tipo carreta. Na avaliação psicológica realizada, seus resultados foram baixos e por isso foram comparados com a primeira avaliação feita cinco anos antes, o que levou a sugerir a ocorrência de um acidente vascular cerebral (AVC), que foi confirmado por um neurologista, e o consequente risco que ele apresentava para dirigir.

\section{Avaliação Psicológica no contexto de concursos públicos}

O reconhecimento da avaliação psicológica no contexto de concursos públicos no Brasil, ocorreu a partir da publicação do Art. 37 da Constituição Federal. Este documento indica que "a investidura em cargo ou emprego público depende de aprovação prévia em concurso público de provas ou de provas e títulos, de acordo com a natureza e a complexidade do cargo ou emprego, na forma prevista em lei" (Senado Federal, 1988). Em seu $39^{\circ}$ artigo, estabelece uma previsão de que sejam realizados exames psicológicos e testes físicos, desde que sejam exigidos para natureza do cargo.

Enquanto uma das etapas de um concurso público, a avaliação psicológica tem como objetivo identificar se as características de um candidato são compatíveis com aquelas que são exigidas em um perfil pré-estabelecido para o cargo (Faiad, Coelho Junior, Caetano, \& Albuquerque, 2012; Maia, \& Queiroz, 2007; Santos, 2016; Thadeu et al., 2012). Na esfera jurídica, para além da seleção daqueles candidatos mais capacitados para o exercício de suas funções, já habilitados para o desempenho do cargo, acrescenta-se o objetivo de se assegurar o princípio de isonomia (Cammarosano, 1984; Fontainha, Geraldo, Veronese, \& Alves, 2015; Santos, 2016).

A avaliação neste contexto se caracteriza por uma forte relação entre dois saberes: a Psicologia e o Direito. Requer do psicólogo o conhecimento profundo das normativas envolvidas no processo, da previsão legal para existência de avaliação no cargo analisado e o entendimento de decisões judiciais e acórdãos resultantes de entendimentos publicados em diferentes esferas do judiciário. Uma das consequências dessa interação está na constante interferência da justiça em aspectos técnicos do processo de avaliação, que vão desde a limitação da aplicação de certas técnicas (como, no exemplo, dinâmicas de grupo), quanto nas reiteradas tentativas de desqualificar essa avaliação por um caráter subjetivo.

Contudo, quanto ao objetivo desta avaliação centra uma expectativa diferenciada por parte da justiça e da sociedade. Espera-se que nesta avaliação também sejam identificados traços de psicopatologia, o que seria possível apenas se houvesse uma avaliação mais 
profunda do candidato, como um processo de psicodiagnóstico (veja Krug, Trentini, \& Bandeira, 2016). Tal entendimento se faz importante por parte dos psicólogos, de forma a não prometerem resultados de uma avaliação que vão além de suas possibilidades. Comumente, o que se tem realizado neste contexto no Brasil é a testagem psicológica (veja Andrade, \& Sales, 2017), por haver um entendimento de que o teste psicológico é a técnica mais justa para tomada de decisão no contexto de concursos públicos (Thadeu et al., 2012).

Enquanto um processo de seleção de pessoal, realizado por meio de avaliação psicológica, faz-se possível coletar informações sobre as características dos candidatos e compará-las com os requisitos definidos no perfil de um cargo a ser pleiteado - requisitos necessários ao bom desempenho da tarefa (Faiad et al., 2012). Por meio do perfil são definidas tais características, como aspectos cognitivos, habilidades específicas e personalidade (Thadeu et al., 2012). Uma das formas mais utilizadas para definição deste perfil, está no estudo científico do cargo, também conhecido como análise profissiográfica ou profissiografia (Faiad et al., 2012). Após esta definição, espera-se que o responsável técnico pelo certame defina as possíveis técnicas que possam ser utilizadas para avaliar tais requisitos. Daí compreende a importância das Resoluções do Conselho, que alinhadas às definições do Satepsi, permitem que o profissional escolha uma lista de instrumentos qualificados que podem ser aplicados.

A partir de sua previsão legal, este processo avaliativo pode ser subdividido em até 15 diferentes etapas, que se modificam a depender da realidade da instituição a que se destina ou da complexidade do certame. Contudo, em comum a todos os processos estão as normativas que são exigidas para esse contexto e que precisam ser avaliadas e estudadas pela psicóloga ou pelo psicólogo responsável pelo processo.

Em 2002, em meio às grandes mudanças propostas no Satepsi, surgiu a primeira Resolução que regulamentou a prática psicológica em processos seletivos de natureza pública e privada (atualmente Resolução $n^{\circ}$ 02/2016). Além de delimitar o objetivo desta avaliação, especificou como obrigatoriedade, que os instrumentos utilizados em certames deveriam estar contemplados na Resolução $n^{\circ}$ 25/2001 (atualmente $n^{\circ}$ 09/2018). Tal prática, como anteriormente discutido, melhor qualificou os concursos públicos. Esta Resolução também estabeleceu alguns procedimentos para as fases do concurso, como por exemplo, a obrigatoriedade de entrevista devolutiva, a necessidade de manutenção do sigilo dos dados e a necessidade de que os psicólogos envolvidos estivessem devidamente inscritos em seus Conselhos Regionais.

Outro importante documento normativo foi publicado no Brasil. No dia 21 de agosto de 2009, a Casa Civil publicou o Decreto $\mathrm{n}^{\circ} 6.944$, elaborado por servidores da área de justiça. Tal documento possuía erros terminológicos e procedimentais, melhorados por um Grupo de Trabalho composto pela Polícia Federal (Corec), em conjunto com alguns membros da CCAP e pesquisadores da área. Foi então produzido o Decreto $\mathrm{n}^{\circ} 7.308$, em 22 de setembro de 2010, definindo regras para as avaliações psicológicas de concursos. Pode-se afirmar que a intervenção da Comissão Consultiva do Satepsi teve papel central na melhoria dos processos seletivos em concursos públicos.

Duas importantes limitações nesta avaliação, estão na publicidade dos testes na internet (Santos, 2016; Thadeu et al., 2012), expondo os testes de forma inadequada e invalidando algumas medidas para essa finalidade. Contudo, vários são os investimentos realizados por pesquisadores da área e editoras, em conjunto com o Satepsi, para o aumento e melhoria das medidas existentes. Neste aspecto surge um importante investimento sobre a importância de estudos que contemplem contextos específicos, contemplado na publicação da Resolução n ${ }^{\circ}$ 09/2018.

Outra questão está na escassez de estudos que demonstrem a importância e a validade desta avaliação. Thadeu e Ferreira (2013) ressaltam sua importância, visto que há um desgaste psicológico que pode ser reduzido, quando o candidato possui um perfil adequado ao cargo. As autoras consideram que tentar se adaptar ao perfil pode propiciar adoecimento físico e/ou mental, além de apresentarem dados preditores de bom desempenho. Em estudo anterior, Brito e Goulart (2005), a partir de uma análise documental realizada numa corporação policial militar, demonstraram que candidatos inaptos em concursos e que entraram na instituição sob liminar (sub judice), demonstraram desvios de conduta em sua atuação. Um dos fatores limitadores de tais estudos, pode ser atribuído ao caráter sigiloso de tais dados.

\section{Avaliação Psicológica no contexto de porte de arma de fogo}

As condições para registro e porte de arma de fogo foram definidas pela Lei Federal $n^{\circ} 9.437 / 1997$. Este documento classificou tipos de crimes, definiu critérios para o porte de arma por civis e legislou o processo de cadastro das armas comercializadas no Brasil. E foi a partir do Decreto 5.123, de julho de 2004, que a avaliação 
psicológica para este contexto foi definida e tornou-se de caráter obrigatório (Lobosque, 2014; Resende, 2017), formalizando a atuação do psicólogo neste contexto, implicando em normas e procedimentos a serem adotados. Conforme apontado por Resende (2017), as legislações sofreram diversas modificações nos últimos anos.

O objetivo da avaliação para concessão do porte de arma de fogo é avaliar se a pessoa possui perfil compatível àquele esperado para trabalhar com uma arma ou, no caso dos civis, ter uma posse e manuseio da mesma (Resolução No018/2008; Resende, 2017). Os critérios normativos são delimitados pela Polícia Federal, pelo Sistema Nacional de Armas (Sinarm), responsável por essa área no Brasil, promulgado pela Lei $\mathrm{n}^{\circ} 10.826 / 03 \mathrm{e}$ por meio de Instruções Normativas (IN) publicadas por este órgão. Tecnicamente, os psicólogos e psicólogas são orientados pela Resolução n ${ }^{\circ}$ 18/2008 do Conselho Federal, que trata sobre essa temática e atualmente regidos pela IN n ${ }^{\circ} 78 / 2014$ (Polícia Federal, 2014).

A IN n ${ }^{\circ} 78$ (Polícia Federal, 2014) também estabelece quais são os documentos necessários para essa prática, como requerimento para credenciamento de psicólogo, laudo psicológico, certificado, portaria de credenciamento de psicólogo, extrato dos indicadores psicológicos do portador de arma de fogo e extrato do perfil profissiográfico do vigilante. Assim, ela define quais são os requisitos que podem ser avaliados pelos psicólogos e psicólogas da área, bem como delimitam a exigência de que seja aplicada uma bateria mínima (Lobosque, 2014; Resende, 2017).

Contudo, Lobosque (2014) afirma que muitas são as limitações desta prática. Apesar da delimitação das características, não se sabe quais são os critérios que levam um candidato a apresentar aptidão ou não. Assim, fica a critério do psicólogo da área tal delimitação, bem como a composição de diferentes baterias para uma mesma finalidade. Ainda mais agravante, a autora identifica que não há, no Brasil, mesmo por parte da instituição norteadora, estudos que justifiquem corretamente a escolha desta bateria mínima de aplicação. Dentre outras limitações encontram-se a falta de estudos que subsidiem a área (Caneda, \& Teodoro, 2012) e a diversidade de avaliações de porte, quando inseridas nas avaliações para concursos públicos (Moraes, \& Faiad, 2016).

Houve, neste processo, uma importante parceria entre o CFP e os psicólogos da Polícia Federal. Em 2014, o CFP lançou uma pesquisa para delimitação do perfil para porte de arma de fogo. Apesar de um grande avanço na área, questiona-se a validade de tal investi- mento, visto que o perfil foi delimitado por psicólogos e, não, por especialistas na área. Lobosque (2014) propôs um estudo de evidência de validade de um perfil estabelecido por especialistas e o Grupo de Pesquisa em Avaliação Psicológica no Contexto de Segurança Pública e Privada, possui um estudo em fase de validação para o Brasil, que diferencia o perfil necessário para manuseio de arma de fogo e sua diferença para os extratos da segurança pública, sociedade e segurança privada (Faiad, et. al., 2016). Mas, conforme apontado por Caneda e Teodoro (2012) o Brasil carece de investimentos que dêem mais subsídios para tal prática.

\section{Considerações finais}

O presente artigo teve como objetivo mostrar o papel do Satepsi, que é o é o Sistema de Avaliação de Testes Psicológicos, na regulamentação das avaliações psicológicas compulsórias, ou seja, aquelas de caráter obrigatório. As avaliações dos contextos de trânsito, concursos e porte/manuseio de arma de fogo objetivam avaliar se uma pessoa, ao executar determinada função, apresenta capacidade e características psicológicas adequadas para sua realização. Possuem em comum a prática do psicólogo referendada por alguma normativa, exigindo deste um melhor preparo e conhecimento técnico para realizá-las. Evidencia, ainda, a importância de normativas que venham a trazer maior definição e qualificação do processo - com o papel central do Satepsi, tanto na produção das Resoluções específicas a cada prática, quanto na busca pelo aprimoramento daquelas normas produzidas por outros órgãos. O Satepsi, enquanto responsável pela avaliação e aprovação dos testes psicológicos que podem ser utilizados pelos psicólogos, passou a garantir a qualidade dos instrumentos e técnicas psicológicos (ou não) utilizados para essas finalidades e, consequentemente, trouxe maior direcionamento para as avaliações compulsórias. Tal fato evidencia a busca por uma proteção da sociedade, que se beneficia com o trabalho de pessoas competentes e preparadas para as funções que são executadas. As funções que apresentam essas exigências se referem à capacidade para dirigir veículos automotores, à possibilidade de portar e usar uma arma de fogo e de atender as pessoas nas diversas funções que são ocupadas por servidores públicos. Apesar da carência de pesquisas nestes contextos apresentados, no que tange a pesquisas que mostrem suas validades, observa-se que muito se avançou nestes últimos quinze anos, desde a criação do Satepsi. 


\section{Referências}

Alchieri, J. C., \& Stroher, F. (2002). Avaliação psicológica no trânsito: o estado da arte no Brasil sessenta anos depois. In R. M. Cruz, J. C. Alchieri, \& J. Sardá, (Org.), Avaliação e medidas psicológicas (vol. 1, pp. 234-345). Itatiba, MG: Casa do Psicólogo.

Alves, I. C. B. (1999). O exame psicotécnico de motoristas. Anais do VIII Congresso Nacional de Avaliação Psicológica (pp. 216-224). Porto Alegre, RS.

Anache, A., \& Corrêa, F. (2010). As políticas do conselho federal de psicologia para a avaliação psicológica. In Conselho Federal de Psicologia (Ed.), Avaliação psicológica: Diretrizes na regulamentação da profissão (pp. 19-30). Brasília, DF: Conselho Federal de Psicologia.

Andrade, J. M., \& Sales, H. F. S. (2017). A diferenciação entre avaliação psicológica e testagem psicológica: questões emergentes. In M. R. C. Lins, \& J. C. Borsa (Orgs.), Avaliação psicológica: aspectos teóricos e práticos (pp. 9-22). Petrópolis, RJ: Vozes.

Borsa, J. C, Damásio, B. F., \& Bandeira, D. R. (2012). Adaptação e validação de instrumentos psicológicos entre culturas: algumas considerações. Paidéia, 22(53), 423-432. https://doi.org/10.1590/1982-43272253201314

BRASIL. Constituição (1988). Constituição da República Federativa do Brasil. Brasília, DF: Senado Federal: Centro Gráfico, 1988. 292 p.

Brito, D. P., \& Goulart, I. B. (2005). Avaliação psicológica e prognóstico de comportamento desviante numa corporação militar. Psico-USF, 10(2), 149-160. https://doi.org/10.1590/S1413-82712005000200006

Cammarosano, M. (1984). Provimento de cargos públicos no direito brasileiro. São Paulo, SP: Revista dos Tribunais.

Caneda, C. R. G., \& Teodoro, M. L. M. (2012). Contribuições da avaliação psicológica ao porte de arma: uma revisão de estudos brasileiros. Aletheia, 38-39, 162-172.

Decreto № 6.944, de 21 de agosto de 2009. Estabelece medidas organizacionais para o aprimoramento da administração pública federal direta, autárquica e fundacional, dispõe sobre normas gerais relativas a concursos públicos, organiza sob a forma de sistema as atividades de organização e inovação institucional do Governo Federal, e dá outras providências. Diário Oficial da União, 24 ago. 2009.

Decreto No 7.308, de 22 de setembro de 2010. Altera o Decreto no 6.944, de 21 de agosto de 2009, no tocante à realização de avaliações psicológicas em concurso público. Diário Oficial da União, 23 set. 2010.

Faiad, C., Coelho Junior, F. A., Caetano, P. F., \& Albuquerque, A. S. (2012). Análise profissiográfica e mapeamento de competências nas instituições de segurança pública. Psicologia: Ciência e Profissão, 32(2), 388-403. http://dx.doi. org/10.1590/S1414-98932012000200009

Faiad, C., Moraes, A. S. Gomes, F. O., Campos, L. C. Mendes., Fonseca, W. R., \& Castro, D. P. V. (2016). Consolidação de um perfil psicológico para porte de arma de fogo. Anais do Congresso de Psicologia Organizacional e do Trabalho, 7.

Fontainha, F. C., Geraldo, P. H. B., Veronese, A. \&, Alves, C. S. (2015). O concurso público brasileiro e a ideologia concurseira. Revista Jurídica da Presidência, 16, 671-702.

Fontana, M. A., \& Fegadolli, C. (2016). Avaliação psicológica no contexto do trânsito: Estudo de caso de motorista com acidente vascular. Boletim de Psicologia, 66(144) 37-46.

Guimarães, L. A. M., Martins, D. A., \& Botelho, A. S. O. (2013). Contribuições para a avaliação psicossocial da norma reguladora 33 (NR-33). Perspectivas em Gestão \& Conhecimento, 3, 57-66.

Justino, Y., Barbosa, A. P. S., \& Pimentel, F. (2017). Avaliação psicológica para submissão ao procedimento bariátrico sob um enfoque analítico comportamental. Psicologia, Saúde \& Doenças, 18(2), 335-347. https://doi. org/10.15309/17psd180205

Krug, J. S., Trentini, C. M., \& Bandeira, D. R. (2016). Conceituação de psicodiagnóstico na atualidade. In C. S. Hutz, D. R. Bandeira, C. M. Trentini, \& J. S. Krug (Orgs.), Psicodiagnóstico (pp.16-20). Porto Alegre, RS: Artmed.

Lei No 9.437, de 20 de fevereiro de 1997. Institui o Sistema Nacional de Armas - SINARM, estabelece condições para o registro e para o porte de arma de fogo, define crimes e dá outras providências. Diário Oficial da União, 21 fev. 1997. 
Lei No 10.826, de 22 de dezembro de 2003. Dispõe sobre registro, posse e comercialização de armas de fogo e munição, sobre o Sistema Nacional de Armas - Sinarm, define crimes e dá outras providências. Diário Oficial da União, 23 dez. 2003.

Lobosque, E. M. G. (2014). Avaliação psicológica para porte de arma de fogo: o que medir afinal? (Dissertação). Universidade Salgado de Oliveira, Rio de Janeiro, RJ.

Maia, M. B., \& Queiroz, R. P. (2007). O regime jurídico do concurso público e o seu controle jurisdicional. São Paulo, SP: Saraiva

Mansur-Alves, M., Silva, R. S., \& Fernandes, S. C. A. (2016). Impact of psychological testing a assessment system (SATEPSI) for scientific publications in psychological assessment. Psico-USF, 21(1) 179-188. https://doi. org/10.1590/1413-82712016210115

Moraes, A. S. \& Faiad, C. (2016). Evidências de validade de um processo seletivo na área de segurança pública. Anais do XII Congresso de Iniciação Científica da UnB (p. 64), Brasília, DF.

Nakano, T. D. C. (2013). Problemas apresentados pelos instrumentos com parecer desfavorável no SATEPSI. Avaliação Psicológica, 12(2), 121-130.

Noronha, A. P. P. (2002). Os problemas mais graves e mais frequentes no uso dos testes psicológicos. Psicologia: Reflexão e crítica, 15(1), 135-142. https://doi.org/10.1590/S0102-79722002000100015

Noronha, A. P. P., Vendramini, C. M., Canguçu, C., Souza, C. V. R., Côbero, C., Paula, L. M. et al. (2003). Propriedades psicométricas apresentadas em manuais de testes de inteligência. Psicologia em Estudo, 8(1), 93-99. https://doi. org/10.1590/S1413-73722003000100012

Polícia Federal. (2014, 5 mar). Instrução Normativa No 78, de 10 de fevereiro de 2014. Estabelece procedimentos para o credenciamento e fiscalização de psicólogos responsáveis pela expedição de comprovante de aptidão psicológica para o manuseio de arma de fogo e regulamenta a atuação do psicólogo na avaliação psicológica do vigilante. Diário Oficial da União.

Primi, R. (2014). Avaliação psicológica e trabalho. In Bendassolli, P. A., \& Borges-Andrade, J. (Org.). Dicionário de Psicologia do trabalho e das organizações (123-128). São Paulo, SP: Casa do Psicólogo.

Primi, R., \& Nunes, C. H. S. (2010). O Satepsi: Desafios e propostas de aprimoramento. In: Conselho Federal de Psicologia-CFP. (Ed.), Avaliação psicológica: Diretrizes na regulamentação da profissão (pp. 129-148). Brasília, DF: Conselho Federal de Psicologia.

Reppold, C. T., Serafini, A. J., Ramires, D. A., \& Gurgel, L. G. (2017). Análise dos manuais psicológicos aprovados pelo SATEPSI para avaliação de crianças e adolescentes no Brasil. Avaliação Psicológica, 16(1), 11-28. https://doi. org/10.15689/ap.2017.1601.03

Resende, M. A. (2017). Avaliação psicológica para concessão do porte de arma de fogo à população e policiais da PMMG. Revista Psicologia: Saúde Mental e Segurança Pública, 3(6), 113-131.

Resolução No 002, de 23 de março de 2003. Define e regulamenta o uso, a elaboração e a comercialização de testes psicológicos e revoga a Resolução CFP n 025/2001. Brasília, DF: Conselho Federal de Psicologia.

Resolução No 002, de 21 de janeiro de 2016. Regulamenta a Avaliação Psicológica em Concurso Público e processos seletivos de natureza pública e privada e revoga a Resolução CFP No 001/2002. Brasília, DF: Conselho Federal de Psicologia. Recuperado de https://site.cfp.org.br/wp-content/uploads/2016/04/Resolução-002-2016.pdf

Resolução No 007, de 29 de julho de 2009. Revoga a Resolução CFP no 012/2000, publicada no DOU do dia 22 de dezembro de 2000, Seção I, e institui normas e procedimentos para a avaliação psicológica no contexto do Trânsito. Brasília, DF: Conselho Federal de Psicologia.

Resolução No 009, de 25 de abril de 2018. Estabelece diretrizes para a realização de Avaliação Psicológica no exercício profissional da psicóloga e do psicólogo, regulamenta o Sistema de Avaliação de Testes Psicológicos - SATEPSI e revoga as Resoluções $n^{\circ} 002 / 2003$, nº 006/2004 e n 005/2012 e Notas Técnicas nº 01/2017 e 02/2017. Brasília, DF: Conselho Federal de Psicologia.

Resolução No 018, de 9 de dezembro de 2008. Dispõe acerca do trabalho do psicólogo na avaliação psicológica para concessão de registro e/ou porte de arma de fogo. Brasília, DF: Conselho Federal de Psicologia.

Resolução $N^{\circ}$ 025, de 30 de novembro de 2001. Define teste psicológico como método de avaliação privativo do psicólogo e regulamenta sua elaboração, comercialização e uso. Brasília, DF: Conselho Federal de Psicologia. 
Resolução No 80, de 19 de novembro de 1998. Altera os Anexos I e II da Resolução no 51/98-CONTRAN, que dispõe sobre os exames de aptidão física e mental e os exames de avaliação psicológica. Brasília, DF: Conselho Nacional de Trânsito.

Resolução $N^{o}$ 267, de 15 de fevereiro de 2008. Dispõe sobre o exame de aptidão física e mental, a avaliação psicológica e o credenciamento das entidades públicas e privadas de que tratam o art. 147 , I e $\$ \S 1^{\circ} \mathrm{a} 4^{\circ} \mathrm{e} \mathrm{o}$ art. 148 do Código de Trânsito Brasileiro. Brasília, DF: Conselho Nacional de Trânsito.

Rueda, F. J. M., \& Monteiro, R. M. (2012). Avaliação da atenção no contexto da Psicologia do trânsito: Análise das publicações na área. In E. Boruchovitch, A. A. A Santos, \& Nascimento, E. (Org.), Avaliação psicológica nos contextos educativo e psicossocial. (pp. 281-299). São Paulo, SP: Casa do Psicólogo.

Santos, A. P. D. (2016). The effects of legal judgments on psychological evaluations in the Brazilian Federal Police. Policing: A Journal of Policy and Practice, 10(2), 113-120. https://doi.org/10.1093/police/p. Av053.

Silva, M. A., Alves, I. C. B., \& Rosa, H. R. (2015). Avaliação psicológica no contexto do trânsito: revisão de literatura do período de 2006 a 2015. Boletim de Psicologia, 65(143), 157-174.

Thadeu, S. H., \& Ferreira, M. C. (2013). A validade da avaliação psicológica em um processo seletivo na área de segurança pública. Revista Iberoamericana de Diagnóstico y Evaluación e Avaliação Psicológica, 2(36), 117-145.

Thadeu, S. H., Ferreira, M. C., \& Faiad, C. (2012). A avaliação psicológica em processos seletivos no contexto da segurança pública. Avaliação Psicológica, 11(2), 229-238.

\section{Cristiane Faiad}

Professora Adjunta do Departamento de Psicologia Social e do Trabalho e do Programa de Pós-Graduação em Psicologia Social, do Trabalho e das Organizações, da Universidade de Brasília (UnB). Mestre e Doutora pela UnB. Coordenadora do Laboratório de Avaliação e Medidas em Psicologia - LABPAM/UnB. E-mail: crisfaiad@gmail.com

\section{Irai Cristina Boccato Alves}

Professora Doutora do Instituto de Psicologia da Universidade de São Paulo. Docente de Graduação e Pós-Graduação e Orientadora de Pós-Graduação. Acadêmica 31 da Academia Paulista de Psicologia. E-mail:iraicba@usp.br

Endereço para envio de correspondência

Universidade de Brasília - Instituto de Psicologia, ICC Sul, Mezanino, Sala A1 031. CEP: 70.910-900

Recebido 20/07/2018

Aprovado 07/08/2018

Received $07 / 20 / 2018$

Approved 08/07/2018

Recibido 20/07/2018

Aceptado 07/08/2018

Como citar: Faiad, C., \& Alves, I. C. B. (2018). Contribuições do Satepsi para Avaliações Psicológicas Compulsórias (Trânsito, Porte de Arma e Concursos Públicos). Psicologia: Ciência e Profissão, 38(n.spe), 50-59. https://doi. org/10.1590/1982-3703000208851

How to cite: Faiad, C., \& Alves, I. C. B. (2018). Satepsi's contributions to Compulsory Psychological Assessments (Traffic, Weapons Carry and Public Contexts). Psicologia: Ciência e Profissão, 38(n.spe), 50-59. https://doi. org/10.1590/1982-3703000208851

Cómo citar: Faiad, C., \& Alves, I. C. B. (2018). Contribuciones del Satepsi para Evaluaciones Psicológicas Compulsivas (Tránsito, Porte de Arma y Concursos Públicos). Psicologia: Ciência e Profissão, 38(n.spe), 50-59. https://doi.org/10.1590/1982-3703000208851 